\title{
Tejiendo espacios queer en Latinoamérica: el travestismo en Herrera Velado y Donoso ${ }^{1}$
}

\section{Jonathan Elí Melgar²}

Recepción: 3 de noviembre de 2015 / Aprobación: 10 de enero de 2016

\section{Resumen}

En esta investigación comparada, me propongo explorar los personajes travestis en "La corrección de menores (Manuscrito de un escolar)", un poema que pertenece a Mentiras y verdades (1923) por el salvadoreño Francisco Herrera Velado (1876-1966), y El lugar sin límites (1966), una novella del chileno José Donoso (1924-1996). Al comparar ambos textos, mi intención no es de contrastar los niveles de sofisticación o estética, sino identificar una línea de textos queer en Centroamérica que podría abrir un nuevo espacio dentro de los estudios queer en Latinoamérica. Específicamente, en este proyecto me enfocaré en una breve contextualización de los estudios queer en Latinoamérica; la inversión de roles sexuales que fue acuñada en el ya clásico ensayo "Escritura/Travestismo" (1969) de Severo Sarduy; la representación de las mujeres en la inversión y la revisión de una interpretación acerca del poema de Herrera Velado.

\section{Palabras clave}

Travestismo; literatura salvadoreña; literatura chilena; estudios queer; diversidad sexual

\section{Abstract}

In this comparative analysis, I investigate the transvestite characters in: "Juvenile Correction (A Student's Manuscript)" (1923) a poem which appears in Lies and Truths (1923) by the Salvadorean Francisco Herrera Velado (1876-1966), and Hell Has No Limits (1966) a novella by the Chilean José Donoso (1924-96). In doing so, rather than comparing aesthetics or the level of sophistication, I intend to identify a line of queer works in Central America that will potentially open a new space in Latin American queer studies. In particular, this research project focuses on: a brief contextualization of queer studies in Latin America; the inversion of roles presented through the analysis in Severo Sarduy's iconic article, "Writing/Transvestism" (1969); the portrayal of women in the inversion, and a (re)reading of a (mis)interpretation of Herrera Velado's poem.

$1 \quad$ Esta investigación se llevó a cabo gracias a la generosidad y apoyo académico de la beca "CCNYStanford Summer Research Program in the Humanities" (2015); mis agradecimientos al Dr. Carlos Riobó y a la Dra. Isabel Estrada del City College of New York (CCNY) y al Dr. Jorge Ruffinelli y a la Srta. Elena Dancu de Stanford.

2 Salvadoreño. Licenciado en Letras Hispánicas por el CUNY, City University of New York y, actualmente, estudiante de la Maestría en Letras Hispánicas por la misma institución. Instructor Adjunto de Español en LaGuardia Community College, CCNY. Correo electrónico: jonathan.e.melgar@gmail.com 


\section{Key Words}

Transvestism; Salvadorean literature; Chilean literature; queer studies; sexual diversity

\section{Resumo}

Nesta investigação comparada, me proponho explorar os personagens travesti em: "A correcção juvenil (Manuscrito de um escolar)" (1923) um poema do salvadorenho Francisco Herrera Velado (1876-1966) e O lugar sem limites (1966) uma novella do chileno José Donoso (1924-96). Na comparação de ambos textos, minha intenção não e do contrastar os nívies de sofisticação ou estética, mas identificar uma linha de textos queer em América Central que poderiam iniciar um novo espaço dentro dos estudos queer em América Latina. Em particular, neste projeto eu me concentro em: uma breve contextualização do estudos queer em América Latina; a inversão de papeis sexuais que foi já cunhada no clássico ensaio "Escritura/Travestismo" (1969) de Severo Sarduy; a representação das mulheres na inversão, e uma releitura de uma interpretação do poema de Herrera Velado.

\section{Palavras chave}

Travestismo; literatura salvadorenha; literatura chilena; estudos queer; diversidade sexual

\section{Introducción}

Clothing is that through which the human body becomes significant and therefore a carrier of signs, even of its own signs [La vestimenta es por la cual el cuerpo humano se vuelve significativo y por lo tanto un portador de signos, incluso de sus propios signos] $]^{3}$ (Barthes citado por Molloy, 1989, p. 408).

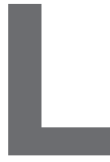

os estudios queer han encontrado un espacio dentro de la crítica literaria latinoamericana desde finales del siglo XX. En este ensayo es mi propósito hacer una comparación de dos obras que tienen muchas características distintas, en cuanto a lo estético ${ }^{4}$, pero que tratan un tema recientemente estudiado por hispanistas, mas no extensamente desarrollado: el travestismo. Se puede especular que tal falta de estudios acerca de este tema en el mundo hispánico se debe a la fuerte presencia homofóbica que aún

3 Citado en "From Serf to Self: The Autobiography of Juan Francisco Manzano" por Sylvia Molloy (1989); asimismo, la traducción del francés al inglés es de Molloy. Originalmente se encuentra en "Encore le corps": "le vêtement est ce par quio le corps humain devient signifiant et donc porteur de signes ou même de ses propres signes" (Barthes, 1982, p. 647).

4 Pienso en lo estético cuando se habla de la manera en que está escrita, ya sea verso o prosa u otra, y los diferentes usos de recursos literarios como metáforas sofisticadas o símiles. Me refiero, también, a que El lugar sin límites es una novela corta (novella) y que "La corrección de menores (Manuscrito de un escolar)" es una leyenda escrita en verso; es decir, es un poema que tiene 448 versos en octava real. 
existe, especialmente en América Latina (Kaminsky, 2008, p. 879). No obstante, hay escritores que rompen las limitaciones y los tabúes, y escriben. Por ejemplo, tanto en "La corrección de menores (Manuscrito de un escolar)" del poemario Mentiras y verdades ${ }^{5}$ (1923) de Francisco Herrera Velado (1876-1966) como en El lugar sin límites6 ${ }^{6}$ (1966) novella de José Donoso (1924-1996) el travestismo forma parte esencial de la trama, ya que ambos personajes principales son travestis: Luisa (n. Luis) en el poema y Manuela (n. Manuel) en la novella. Hay que notar, sin embargo, que mi propósito no es rescatar la obra de Herrera Velado ni de comparar la calidad de su escritura con la de Donoso; intento exponer una línea de escritura queer en El Salvador en el siglo XX, que hace falta en Centroamérica en comparación con la variada escritura queer existente en el Cono Sur y el Caribe. Encuentro, sin duda alguna, importante identificar un corpus de literatura queer en Centroamérica para entender, en su totalidad, qué significa esta tendencia literaria en Latinoamérica. Específicamente, este ensayo busca realizar lo siguiente: 1) dar una breve contextualización de los estudios queer en Latinoamérica; 2) investigar la diversa representación del personaje travesti y los aspectos queer en ambas obras; 3) mostrar y aplicar la teoría de la inversión de géneros de Severo Sarduy en la obra de Herrera Velado; 4) examinar cómo las mujeres son retratadas en el canjeo de roles sexuales, y 5) proponer una relectura de la única interpretación queer del poema de Herrera Velado.

\section{Un breve panorama sobre lo queer en Latinoamérica}

Hacer un análisis comparativo que tenga como enfoque releer los textos elegidos desde un lente queer tiene sus complicaciones, ya que, en sí, el complemento adverbial queer se tiene que escribir en bastardilla por ser un vocablo anglosajón ${ }^{7}$. No obstante, como he mencionado antes, desde finales del siglo XX, estudiosos, ya sea críticos extranjeros/foráneos a los estudios hispánicos e hispanistas, han optado por utilizar la palabra queer para referirse a obras que tienen que ver con la temática de "identidades sexuales no heteronormativas (gay, lesbiana, bisexual, travesti, transgénero, intersexual, transexual)" (Martínez, 2008, p. 864).

El primer trabajo que se clasificó a sí mismo como queer, que meramente se enfoca en los estudios hispánicos y abrió las puertas a los estudios queer, fue ¿Entiendes? Queer Reading, Hispanic Writing (1995) editado por Emilie Bergmann y Paul Julian Smith. Y, aunque ha habido una reciente incorporación de la palabra queer en la crítica hispánica, desde el principio se ha puesto en discusión la traducción literal al castellano o la metamorfosis lingüística que

$5 \quad$ Nótese que usaré la segunda edición (1977) de Mentiras y verdades.

6 En el caso de El lugar sin límites, utilizaré la edición de 1999.

7 Consultar los siguientes ensayos para ampliar el debate sobre el término queer en la crítica latinoamericana: "Hacia un verbo queer" de Amy Kaminsky (2008) y "Transformación y renovación: los estudios lésbicos-gays y queer latinoamericanos” de Luciano Martínez (2008). 
a veces se ve en el castellano/crítica latinoamericana cuando las teorías son foráneas. En el caso de la teoría queer, Amy Kaminsky, en su lúcido artículo "Hacia un verbo queer", utiliza "encuirar" sugiriendo que:

desvestir no solamente para mostrar la realidad debajo de la vestidura engañosa -el outing clásico-, sino también como una forma de deconstrucción. Cuestiona la estabilidad de las normas. Revela la inestabilidad de la identidad y, paradójicamente, revela también la necesidad de crear y defender identidades alternativas para sobrevivir en una cultura regida por la identidad normatizada [el énfasis no es del original] (Kaminsky, 2008, p. 879).

Desde el comienzo del ensayo, la autora nos da una definición, desde su propia perspectiva, acerca del término queer, con un toque de castellano al ponerlo en forma infinitiva en la categoría de los verbos que terminan en -ar. Asimismo, ella hace mención de otras adaptaciones que ha tenido el vocablo, como por ejemplo: "ciurpo" y "queerpo", ambos para referirse a cuerpo queer; la frase "queeremos saber", otra combinación de palabras que juega con la raíz queer, y "hacer queering" apropiado por la española Paloma Fernández Rasines y que tiene como plano: "señala[r] el paso de nombrar una identidad clandestina y sacarla del armario a activar un proceso transformativo en la cultura" (Kaminsky, 2008, pp. 887-888). Todos estos ajustes reflejan la complejidad de la palabra y del significado, en sí, en los estudios queer en Latinoamérica, y cómo este ha ido evolucionando. Además de las definiciones que se han dado, en este ensayo se utilizará la palabra "queer" para encasillar cualquier elemento raro, el cual proviene literalmente de la definición en su origen anglosajón.

Ahora bien, como se ha dicho desde el principio, los estudios queer en Latinoamérica se han enfocado usualmente en el Cono Sur o en el Caribe. No obstante, no pueden pasar desapercibidos los intentos que críticos centroamericanistas han hecho por incorporar un eje distinto a las interpretaciones sobre la cultura y literatura centroamericana ${ }^{8}$. Asimismo, reconozco que los académicos militantes queer que han tratado el tema de la sexualidad a profundidad son: Rafael Lara Martínez (El Salvador), quien se ha enfocado en escritores del canon salvadoreño, y Uriel Quesada (Costa Rica), quien, además de ser académico, es también escritor.

8 Véase las ediciones especiales de revistas académicas en cuanto al tema de la sexualidad: "Sexualidades en Centroamérica" (No. 19, Julio-Diciembre, 2009) en Istmo: Revista virtual de estudios literarios y culturales centroamericanos (recuperado de http://istmo.denison.edu/n19/articulos/index.html), especialmente el ensayo sobre travestismo: "El gato de sí mismo: novela de la travestización" de José Pablo Rojas González, y "Géneros, sexualidades y diversidades" (Vol. 11, No. 2, 2014) en Cuadernos Inter.c.a.mbio sobre Centroamérica y el Caribe, en particular los siguientes ensayos que tratan lo queer: "Gente queer: masculinidades femeninas y el dilema de las identidades" de Álvaro Carvajal Villaplana; "La patologización de la transexualidad: contemplando posibilidades de resistir desde algunas construcciones identitarias de género no hegemónicas" de Mario Andrés Soto Rodríguez, y "Controlando y regulando el cuerpo, la sexualidad y la maternidad de las mujeres centroamericanas (siglo XIX e inicios del siglo XX)" de Eugenia Rodríguez Sáenz. Todos los artículos mencionados pueden ser consultados en http://revistas.ucr.ac.cr/index.php/intercambio/issue/view/1653/showToc 
En la definición de encuirar planteada por Kaminsky, la autora utiliza un verbo que me llama la atención para tratar de definir el travestismo: "desvestir", ya que el travesti se desviste de hombre para vestirse de mujer, pero no la imagen del Otro sino su propia representación. De acuerdo con Sifuente-Jáuregui: "transvestism is [not] about representiong the other [but rather] Transvestism is about representing the Self [El travestismo [no] es sobre la representación del Otro [sino] el travestismo es sobre la representación del yo]" (Sifuentes-Jáuregui, 2002, p. 3). Luego, Kaminsky menciona que "no solamente para mostrar la realidad debajo de la vestidura engañosa -el outing clásico-, sino también como una forma de deconstrucción" (Kamisnky, 2008, p. 879). De manera semejante, el travesti, como se ha mencionado, se quita la vestimenta engañosa para destruir y (re)construir su imagen propia.

En cuanto a la metodología que usaré para el análisis de las obras "La corrección de menores (Manuscrito de un escolar)", de Francisco Herrera Velado, y El lugar sin límites, de José Donoso, indico que se trata de una investigación cuyo eje es la comparación, es decir, se trata de emplear un diálogo queer de inversiones entre los protagonistas, quienes son travestis.

\section{Publicación de las obras: El Salvador y Chile}

En muchas ocasiones el contexto histórico de las publicaciones funciona como puente entre el subtexto de la trama y la historia en el texto. En el caso de la obra de Francisco Herrera Velado, el poema, "La corrección de menores (Manuscrito de un escolar)", fue publicado en Mentiras y verdades (1923), una colección de leyendas en verso. Asimismo, Roque Dalton (1935-1975) lo incorpora en su libro Las historias prohibidas del Pulgarcito (1974), esta fue la segunda publicación del poema. Se puede especular que Dalton alude que este poema formó parte de "las historias prohibidas" por su tema tan alarmante sobre las sexualidades no heteronormativas: el travestismo y el lesbianismo?. Además, Horacio Castellanos Moya en su artículo "Dalton: Correspondencia clandestina (1973-1975) (Segunda parte)" expone la correspondencia entre Dalton y Aída Cañas (la ex cónyuge de Dalton) para mostrar que, en una de sus cartas, perteneciente al archivo de la familia Dalton, Dalton escribe: "si tienes a mano el librito de don Chico Herrera Velado que me regaló la Orbe, Mentiras y verdades, me lo mandas también con mi señora" (Castellanos Moya, 2013, p. 5). Esto indica que Dalton ya conocía ese texto antes de que la segunda edición apareciera; la segunda edición de Mentiras y verdades se llevó a cabo en 1977 por la editorial Ministerio de Educación, que ha tratado de rescatar las obras que fueron olvidadas o censuradas.

9 La temática lésbica se explorará brevemente cuando se hable sobre el rol de las mujeres en la inversión. 
Además, la obra de Francisco Herrera Velado no ha sido estudiada fuera de El Salvador como la de Salarrué o Dalton ${ }^{10}$. Esto se debe, en gran parte, a la carencia del elemento "sublime", ya que generalmente los escritos de Herrera Velado reflejan un período en especial y no transcienden ${ }^{11}$. Al contrario, El lugar sin límites, la tercera novela de Donoso, publicada en 1966, ha sido considerada como una de las novelas canónicas del llamado boom latinoamericano, al cual Donoso perteneció y escribió su experiencia y perspectiva en Historia personal del "boom" (1972).

\section{Lo raro/queer en ambas obras}

Aunque la fecha de publicación indique un esquema diferente en el contexto histórico, hay que observar que, tanto la década de 1920 como en la de 1960, la temática travesti o queer no era aceptable. Sin embargo, debido al surgimiento de las teorías literarias culturales en los setenta, las lecturas y relecturas se han apoderado del mundo académico universal. Es decir, la lectura por medio de una perspectiva queer en la obra de José Donoso no es nada novedosa, incluso, se han publicado demasiadas críticas queer sobre la escritura donosiana -especialmente en sus obras notorias El lugar sin límites y El obsceno pájaro de la noche (1970). Asimismo, la única lectura que expone algunos de los elementos queer en el poema de Herrera Velado es el valioso capítulo: "Travestismo-(Homo)Sexualidad-Pederastia" incluido en el libro Indígena, cuerpo y sexualidad en la literatura salvadoreña de Rafael Lara-Martínez. Más adelante, como uno de los puntos finales, se observan algunas de las complicaciones de la interpretación de Lara-Martínez.

Al estudiar las comparaciones de los estudios que se han hecho sobre lo queer en ambas obras, hay que percatarse de las definiciones dadas anteriormente sobre el tema. Para comenzar a contrastar los elementos, utilizaré la terminología de raro/a para referirme a lo queer. Tanto en el poema de Herrera Velado como en la novella de Donoso, hay personajes o ejemplos que sostienen el aspecto raro. En el caso de "La corrección de menores (Manuscrito de un escolar)", tomaré el personaje principal, Luis o Luisa, como ejemplo; y, en el caso de El lugar sin límites, me enfocaré en la Japonesita, hija de la Japonesa Grande y la Manuela, ya que es el personaje que menos atención ha recibido mediante un lente queer.

10 Estos dos autores son los escritores salvadoreños que más se han destacado internacionalmente, tanto en el mercado editorial como en la academia, Salarrué durante la primera mitad y Dalton en la segunda del siglo XX.

11 Herrera Velado es conocido dentro de la literatura salvadoreña por su libro de leyendas en verso, Mentiras y verdades (1923) y, su libro de tradiciones y cuentos, Agua de coco (1926), el cual ha tenido varias ediciones, fue traducido al ruso y publicado en la URSS (Dalton, 1974, p. 93). Además de esas obras, Herrera Velado es autor de los poemarios Fugitivas (1909) y La torre del recuerdo (1926), pero no son muy leídos y, mucho menos, estudiados. 
Los personajes forman una parte importante de la trama e historia del texto; por medio de ellos, el lector se da cuenta de diferentes figuras retóricas que la voz narrativa utiliza para jugar con el lector, o ayudan a apoyar temas centrales en la obra. En el poema de Herrera Velado, Luis o Luisa se describe desde el mero comienzo como raro/a o queer. La voz poética hace mención del personaje principal por medio de:
Un célebre doctor hizo el diagnóstico
de que hay desequilibrios en mi brújula,
por mis raras tendencias al acróstico
[el énfasis no es del original] (Herrera Velado, 1923, p. 141).

Dado que se escribe a principios del siglo XX, todavía se pueden ver rasgos de otros movimientos literarios del siglo XIX, por ejemplo, la incorporación científica del doctor y un diagnóstico son modalidades muy románticas. No obstante, el doctor juega un papel importante en esta cita ya que se relaciona con los estudios de géneros biológicos -macho y hembra-, la antítesis de los estudios queer. Asimismo, los resultados de dicho diagnóstico van en contra de la definición convencional de la normalidad en una sociedad y cuestionan el orden jerárquico biológico; también, hay que resaltar la manera en que la voz narrativa describe lo queer por medio de una imagen de la brújula (cuerpo), mientras que el desequilibrio (queer) y los desequilibrios son ocasionados por las "raras tendencias"12. Del mismo modo, tanto en el caso de la novela como en el poema se utiliza textualmente el vocablo: rara, y, por supuesto, en la clasificación gramatical de femenino ya que representa visualmente el género sexuado: el travestismo. Siguiendo la misma idea de la importancia de los personajes en una obra, en comparación, la Japonesita, en el texto de Donoso, es descrita de la siguiente manera:

Y cuando lo embromaban recordándole que fuera como fuera la Japonesita era hija de la Manuela, el tonelero se reía sin creer. Pero la Japonesita creció y nadie pudo dudar: flaca, negra, dientuda, con mechas tiesas igualitas a las de la Manuela (Donoso, 1966, p. 118).

La Japonesita siendo una semilla, una flor, un fruto de la Japonesa Grande y la Manuela, encarna lo que se considera como raro y se puede argumentar que dichas características raras provienen del padre como lo afirma la cita: "flaca, negra, dientuda, con mechas tiesas igualitas a las de la Manuela". Es importante hacer hincapié, también, en el tema tratado en la escena, ya que cuando la voz narrativa menciona "recordándole" hace referencia al acto sexual (performance) que ocurrió entre la Japonesa Grande y la Manuela, y que triunfan, una vez más, los aspectos biológicos a favor de la normalidad de una sociedad, pero que como resultado final sale un personaje queer: la

12 Es importante destacar que la palabra "tendencia" fue utilizada por mucho tiempo como sinónimo de acciones o comportamientos que se asociaban a la homosexualidad. 
Japonesita. Sin embargo, el comportamiento de la Japonesita, argumentaré, es el aspecto raro más fuerte y se ve cuando,

A pesar de que todas las chiquillas eran buenas con ella, la Japonesita se arrancaba, se iba a esconder ... y nunca salía a la calle a jugar ni nada y no saludaba a nadie ... Ahora, toda la gente decente le tiene pena a la Japonesita, tan rara la pobre [el énfasis no es de orginal] (Donoso, 1966, p. 127).

En esta escena se delata la conducta de la Japonesita, lo cual refleja lo rara que ella es en una sociedad, en El Olivo. Inclusive, la Manuela textualmente la llama "rara", pero todo esto es resultado de sus orígenes biológicos y rompe con el esquema de "identidad normatizada", ya que no juega un papel normativo desde la infancia y su oficio, administradora de finanzas del prostíbulo, es un trabajo regulado por el mundo masculino (Donoso, 1966, p. 113).

\section{La inversión queer}

Como se ha mencionado previamente, desde su primera publicación en 1966, El lugar sin límites ha sido punto central de muchos estudios que se han enfocado en el tópico de "el mundo al revés" tomando ejemplos de distintas escenas pero, en particular, con un énfasis en el papel que juegan los personajes: la Manuela, la Japonesa Grande y Pancho, en cuanto a los géneros sexuales. Es decir, la teoría de la inversión ${ }^{13}$ en la notoria novela de José Donoso no es nada innovador e, incluso, Severo Sarduy, por primera vez, lo menciona en su artículo "Escritura/Travestismo" (1969), tres años después de la primera publicación. Este estudio de Sarduy ha sido una fuente fundamental para los estudios de la novela de Donoso. No obstante, el aspecto crucial de este estudio no es centrarse en tal caso, sino tomar dicha teoría, que se ve claramente en la novella, y compararla con un texto híbrido en verso publicado casi 40 años antes que la obra de Donoso: "La corrección de menores (Manuscrito de un escolar)" (1923) de Francisco Herrera Velado.

Sin embargo, ¿qué es la inversión queer y cómo se ve? Hablar de una inversión tiene repetitivamente como significado "homosexual", ya que inversión/ sodomía son sinónimos de homosexualidad. Sin embargo, la frase de "inversión queer" no ha sido utilizada en ningún tipo de estudios en relación con la escritura donosiana. Entonces, en este ensayo se utiliza inversión para manifestar la teoría y los estudios que se han hecho en cuestión del tópico del "mundo al revés" igualmente, paradójica y repetitivamente, se utiliza queer para hacer énfasis no

13 Además del ensayo crucial de Sarduy, véase los siguientes escritos sobre la inversión: "La inversión como norma: a propósito de El lugar sin límites" (1975) de Fernando Moreno Turner; "La inversión como aproximación al mundo femenino en algunos relatos de José Donoso" (1983) por Sandra M. Boschetto; "Gender Without Limits. Transvestism and Subjectivity in El lugar sin límites"(1997) de Ben Sifuentes-Jáuregui, y "Espacio y sexualidad en El lugar sin límites de José Donoso" (1999) de Andrea Ostrov. 
solamente en la inversión de roles sexuales, sino también para darle doble fuerza a los estudios queer en Latinoamérica, en Centroamérica y en El Salvador.

A manera de ilustración, hay una escena en El lugar sin límites donde la voz narrativa relata una actuación (performance) sexual entre la Manuela ${ }^{14}$, personaje principal que es travesti, y la Japonesa Grande, gerente y prostituta de un prostíbulo, quien se vuelve dueña del burdel después de la escena. En dicho acto, que es una apuesta, la Manuela juega el papel de la "mujer" y la Japonesa Grande asume el papel de "hombre", lo cual resulta en la evidencia de la teoría de inversión de géneros sexuales o inversión queer en la novela de Donoso (Donoso, 1966, pp. 189-91) ${ }^{15}$. Asimismo, Sarduy en su artículo previamente mencionado propone que: "La Manuela, que novelísticamente (gramaticalmente) se significa como mujer -primera inversión-, funciona como hombre, puesto que es en tanto que hombre que atrae a la Japonesa" (Sarduy, 1969, p. 44), lo cual sostiene aún más la complejidad de la inversión, ya que ocurren inversiones dentro de otras inversiones; es decir, es un ciclo de inversiones.

De igual magnitud, existe una escena en "La corrección de menores (Manuscrito de un escolar)" donde los papeles de los personajes se cuestionan hasta llegar a un punto de inversión queer. Además, el personaje principal no tiene clara su identidad sexual:

Me llamo Luis, pero me dicen... "Luisa"

No os pongáis a reír, que soy muy hombre

(Herrera Velado, 1923, p. 142).

Esta cita nos demuestra que se trata de un caso queer, o para ser más específico: travesti. Es el mismo caso de travestismo que la Manuela. Y, como en El lugar sin límites con Manuela, Luisa también tiene una relación sexual con una mujer; no obstante, una de las grandes distinciones es que Luisa tiene sentimientos amorosos hacia Pura, que es el otro personaje que forma parte del acto sexual. Como es de esperarse, la manera que Herrera Velado matiza la inversión queer es más lírica:

El caso de Romeo y de Julieta...

mas Julieta era yo, y ella Romeo (Herrera Velado, 1923, p. 145).

De la misma manera que la voz narrativa en la novela muestra la inversión queer con "no, no, tú eres la mujer, Manuela, yo soy la macha" (Donoso, 1966, p. 190), la voz poética sugiere que Luisa, que es hombre biológicamente, es

14 Manuel González Astica es su nombre de nacimiento -la identidad biológica impuesta-, y se menciona hasta al final de la novela.

15 Por si se opta por la versión directamente textual sobre el acto: "no, no tú eres la mujer, Manuela, yo soy la macha" (Donoso, 1966, p. 190). Además, el valor de la obra y escena reside en que: "En el interior de esta inversión surge otra: en el acto sexual el papel de la Manuela, hombre por atribución narrativa, es pasivo. No femenino -por eso se trata de una inversión dentro de otra y no de un simple regreso al travestismo inicial-, sino de hombre pasivo, que engendra a su pesar ... Ella (La Japonesa) es el elemento activo del acto" (Sarduy, 1969, p. 44). 
Julieta en el acto sexual y que Pura, que es hembra, hace la función del Romeo. Para ver las diferentes inversiones que Sarduy indica acerca El lugar sin límites, véase el siguiente esquema:

\begin{tabular}{|c|l|}
\hline \multicolumn{2}{|c|}{ CUADRO No. 1. INVERSIONES } \\
\hline \multicolumn{1}{|c|}{ Inversiones [de la Manuela] } & \multicolumn{1}{c|}{ Inversiones de Luisa } \\
\hline $1^{\mathrm{a}}$ un hombre se travesti en mujer & $1^{\mathrm{a}}$ un hombre lo travisten en mujer \\
\hline $\begin{array}{l}2^{\mathrm{a}} \text { que atrae por lo que de hombre } \\
\text { hay en ella }\end{array}$ & $\begin{array}{l}2^{\mathrm{a}} \text { que atrae por lo que de mujer hay } \\
\text { en ella }\end{array}$ \\
\hline $3^{\mathrm{a}}$ que es pasivo en el acto sexual & $3^{\mathrm{a}}$ que es pasivo en el acto sexual \\
\hline $\begin{array}{l}\text { Fuente: Inversiones [de la Manuela] (Sarduy, 1969, p. 45) [el énfasis no es del original]. Inversiones de } \\
\text { Luisa (elaboración propia con base en Sarduy, 1969). }\end{array}$ \\
\hline
\end{tabular}

Solamente la última inversión concuerda con el gráfico de Luisa adaptado con base en el diseño de Sarduy. En El lugar sin límites, la decisión de travestirse es unánime; es decir, la Manuela lo hace porque quiere y está consciente del acto. Al contrario, Luisa, en el "La corrección de menores (Manuscrito de un escolar)", se ve travestido obligatoriamente por otro personaje que representa la autoridad sobre el cuerpo del personaje principal:

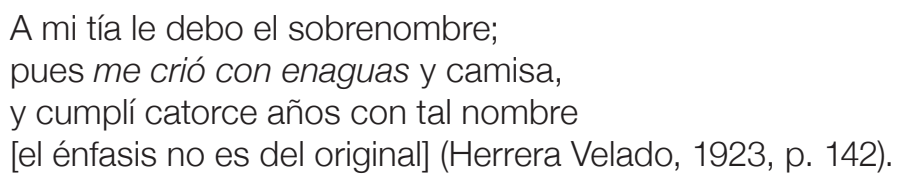

A mi tía le debo el sobrenombre; pues me crió con enaguas y camisa, y cumplí catorce años con tal nombre [el énfasis no es del original] (Herrera Velado, 1923, p. 142).

Cuando la voz lírica menciona el "sobrenombre" señala el nombre de Luisa en lugar de Luis. La segunda inversión se explicará cuando se toque el tema del papel de las mujeres en la inversión queer; en la tercera inversión, Luisa es pasivo/a en el acto sexual.

\section{Las mujeres en la inversión queer}

Después de haber comparado las tres inversiones que hay en El lugar sin límites con las que se presentan en "La corrección de menores (Manuscrito de un escolar)", se cuestionará la sexualidad de las mujeres para llegar a una conclusión. En la novela de Donoso la mujer que participa en el acto es la Japonesa Grande y en el poema es Pura. Hay que notar inmediatamente que el nombre es simbólico ya que de "pura" no tiene mucho, pues la voz poética la retrata como:

una hija divinal y seductora de inmensa devoción y travesura ...

$98 \quad$ Era mayor que yo, más vivaracha (Herrera Velado, 1923, p. 144). 
Se puede argumentar que el uso del vocablo "vivaracha" tiene doble significado puesto que fonológicamente hace alusión a marimacha ${ }^{16}$, especialmente por tener la misma rima consonante; y luego la voz poética afirma tal especulación cuando menciona: "con gustos de muchachos, la muchacha..." (Herrera Velado, 1923, p. 144); es decir, a Pura le gustan las mujeres. Entonces, la segunda inversión que lista Sarduy no combina con el personaje de Luisa, el personaje de Luisa: a Pura no le llamó la atención lo que de hombre había en Luis, sino que Pura pensó que Luisa era mujer. La orientación sexual de ambas mujeres en las obras es distinta, ya que la Japonesa Grande es heterosexual o le atraen los hombres, como argumenta Sarduy al destacar la segunda inversión.

Sin embargo, Sifuentes-Jáuregui, en su artículo "Gender without Limits: Transvestism and Subjectivity in El lugar sin límites", menciona que: "La Japonesa has had sex with other women before. Her words unwittingly leak that secret [La Japonesa ha tenido sexo con otras mujeres en el pasado. Sus palabras involuntariamente filtran ese secreto]: "look, like so, you see, the legs intertwined [mira, así, ves, las piernas entretejidas]" and also "I'm the butch [yo soy la macha]" (Sifuentes-Jáuregui, 1997, p. 53), dicha interpretación tiene en torno una perspectiva acerca del acto sexual entre la Manuela y la Japonesa Grande, y Sifuentes-Jáuregui lo nombra como un acto lesbiano ${ }^{17}$, pero si fuera así no cabe dentro de la categoría de inversiones porque los elementos biológicos, hembra y macho versus hembra y hembra en el caso lesbiano, no se retratan en ninguno de los textos, tanto en la novella como en el poema. Hay citas textuales que se pueden leer como deseos lésbicos en El lugar sin límites, pero que lógicamente no pueden ser, como el caso expuesto sobre el acto sexual entre la Manuela y la Japonesa Grande. No obstante, en el poema sí se pueden ver potentes pretensiones lésbicas directamente con el personaje de Pura, como se ha explicado previamente.

\section{Otras implicaciones y conclusión}

En el importante libro Indígena, cuerpo y sexualidad salvadoreña (2012), Lara-Martínez le dedica un capítulo al poema de Herrera Velado -además de incorporar el poema completo en el libro. Es el primer y único libro de esta índole sobre los estudios de la literatura salvadoreña, es por eso que lo considero importantísimo. Sin embargo, cuando el autor expone el/lo(s) acto(s) sexual(es) de Luis/Luisa, él menciona que hubo dos relaciones: "la primera resulta bastante singular, ya que su pareja es lesbiana: 'con gustos de muchacho, la muchacha'”.

16 Marimacha en vocablo salvadoreño es sinónimo de lesbiana.

17 Además, Sifuentes-Jáuregui menciona que "it is worth mentioning that pecho de palo may also means "flat-chested," and from this I am tempted to speculate that she [la Japonesa] too was a transvestite [Vale la pena mencionar que 'pecho de palo' puede asimismo significar 'pecho plano' y por lo tanto sospecho que ella [la Japonesa] es también travesti]” (Sifuentes-Jáuregui, 1997, p. 61). En esta escena se refiere al nombre (pecho de palo) de otro prostíbulo donde la Manuela y la Japonesa trabajaban. 
Luego expone que: "En cambio, la segunda relación amorosa lo marca de por vida. Se relaciona con Pura", y al final argumenta que: "Luis afirma su identidad varonil y guarda de Pura una memoria entrañable que lo carcome la distancia: "De la irrisión de la niñez pasada/ sólo un recuerdo me consuela: Pura" (LaraMartínez, 2012, p. 149). Cuando el autor se refiere a la primera y segunda, en realidad, es la misma persona: Pura. Véase a continuación la parte del poema donde se menciona la supuesta "primera" hembra del poema y a Pura, y se podrá constar que en realidad se trata de una misma persona:

III

Vivía en la parroquia una señora, prima de don Carmelo el señor cura, quien no obstante lo buena y rezadora tenía un ángel condenado. Pura, una hija divinal y seductora de inmensa devoción y travesura; y llevábame a ver la sacristía, con gran satisfacción para mi tía.

Era mayor que yo, más vivaracha, de ojos hondos y azules como lagos; con gustos de muchacho, la muchacha... unos antojos y caprichos vagos... Yo era el machete de la floja cacha, pues había vivido en otros pagos; y sentía en la vértebra cosquillas cuando ella me sentaba en sus rodillas.

Y conocimos la maldad secreta de bostezar en misa y jubileo, de ansias sin nombre la amistad inquieta que es en las niñas precursor deseo. El caso de Romeo y de Julieta... mas Julieta era yo, y ella Romeo. Buscábame afanosa, me quería, Con gran satisfacción para mi tía.

Pura llegaba mucho a nuestra casa; éramos dos muy íntimas chicotas; cual dice la academia, "muy del asa". Pura cosía mis enaguas rotas, Todo entre risas e inocente guasa, causando envidia a las demás devotas por celos al honor que nos hacía... con gran satisfacción para mi tía (Herrera Velado, 1923, pp. 144-145). Pura. Luego, en el estrofa seguiente se describe la "primera relación amorosa" 
de Luisa; no obstante, ni en el poema ni en el análisis de Lara-Martínez se mencionan nombres de ese primer amor. En la tercera estrofa de la III parte, la voz poética describe el acto sexual, donde se puede ver la inversión queer. Entonces, cuando la voz lírica hace referencia a Pura al final del poema, ciertamente, se refiere a la lesbiana con quien sostuvo una relación sexual y contradice completamente el argumento de Lara-Martínez sobre la afirmación "varonil” de Luisa.

Sin duda alguna los estudios queer en Latinoamérica cada vez se están haciendo más comunes entre los críticos literarios; sin embargo, como en cualquier campo de estudio, la región de América Central es la menos estudiada. Con la intención de integrar a Centroamérica, se propone que los nuevos estudiantes o estudiosos centroamericanistas expongan obras queer que traten una temática similar a textos que ya son conocidos en el mundo literario latinoamericano o universal. De esta forma, la definición de la literatura queer latinoamericana tomará un rumbo distinto al que ya se conoce. Espero que este ensayo comparado haya podido demostrar las similitudes y diferencias en "La corrección de menores (Manuscrito de un escolar)" de Francisco Herrera Velado y El lugar sin límites de José Donoso. En particular, la contextualización y los aspectos queer; la inversión queer; el papel de las mujeres en la inversión queer, y una corrección de una interpretación sobre el poema de Herrera Velado.

\section{Referencias}

Barthes, Roland. (1982) [1978]. Encore le corps. Critique, 423(4), 645-654.

Boschetto, Sandra M. (1983). La inversión como aproximación al mundo femenino en algunos relatos de José Donoso. Hispania, 66(4), 532-541. Recuperado de http://www.jstor.org/stable/341464

Bergmann, Emilie L. \& Julian Smith, Paul (eds.). (1995). Entiendes?: Queer Readings, Hispanic Writings. Durham: Duke University Press.

Carvajal Villaplana, Álvaro. (2014). Gente queer: masculinidades femeninas y el dilema de las identidades. Cuadernos Inter.c.a.mbio sobre Centroamérica y el Caribe, 11(8), 177-143. Recuperado de http://revistas.ucr.ac.cr/index. php/intercambio/article/view/16312/15814

Castellanos Moya, Horacio. (2013). Dalton: Correspondencia clandestina (19731975) (Segunda parte). lowa Literaria, 1-7. Recuperado de http://thestudio. uiowa.edu/iowa-literaria/?p=2391

Dalton, Roque. (1997) [1974]. Las historias prohibidas del Pulgarcito. México: Siglo XXI.

Donoso, José. (1998) [1972]. Historia personal del "boom". Madrid: Alfaguara.

Donoso, José. (1999) [1969]. El lugar sin límites. Madrid: Cátedra. 
Donoso, José. (1999) [1970]. El obsceno pájaro de la noche. Madrid: Alfaguara.

Herrera Velado, Francisco. (1909). Fugitivas. San Salvador: La Unión.

Herrera Velado, Francisco. (1923) [1961]. Agua de coco. San Salvador: Ministerio de Educación.

Herrera Velado, Francisco. (1932) [1926]. La torre del recuerdo. San Salvador: La Unión.

Herrera Velado, Francisco. (1977) [1923]. Mentiras y verdades. San Salvador: Ministerio de Educación.

Kaminsky, Amy. (2008). Hacia un verbo queer. Revista Iberoamericana, 74(225), 879-895. Recuperado de http://revista-iberoamericana.pitt.edu/ojs/index. php/lberoamericana/article/viewFile/5215/5373

Lara-Martínez, Rafael. (2012). Travestismo-(Homo)Sexualidad-Pederastia. En Rafael Lara-Martínez (ed.), Indígena, cuerpo y sexualidad en la literatura salvadoreña. San Salvador: Editorial Universidad Don Bosco.

Martínez, Luciano. (2008). Transformación y renovación: los estudios lésbicosgays y queer latinoamericanos. Revista Iberoamericana, 74(225), 861-876. Recuperado de http://revista-iberoamericana.pitt.edu/ojs/index.php/lberoamericana/article/view/5214/5372

Molloy, Sylvia. (1989). From Serf to Self: The Autobiography of Juan Francisco Manzano. MLN, 102(2), 393-417. Recuperado de http://www.jstor.org/stable/2905146

Moreno Turner, Fernando. (1975). La inversión como norma: a propósito de El lugar sin límites. Cuadernos hispanoamericanos, (295), 19-42. Recuperado de http://dialnet.unirioja.es/servlet/articulo?codigo=2032003

Ostrov, Andrea. (1999). Espacio y sexualidad en El lugar sin límites de José Donoso. Revista Iberoamericana, 65(187), 341-348. Recuperado de http:// revista-iberoamericana.pitt.edu/ojs/index.php/lberoamericana/article/ viewFile/6076/6252

Rodríguez Sáenz, Eugenia. (2014). Controlando y regulando el cuerpo, la sexualidad y la maternidad de las mujeres centroamericanas (siglo XIX e inicios del siglo XX). Cuadernos Inter.c.a.mbio sobre Centroamérica y el Caribe, 11(8), 233-258. Recuperado de http://revistas.ucr.ac.cr/index.php/ intercambio/article/view/16766/16257

Rojas González, José Pablo. (2009). El gato de sí mismo: novela de la travestización. Istmo: Revista virtual de estudios literarios y culturales centroamericanos, (19). Recuperado de http://istmo.denison.edu/n19/articulos/4.html 
Sarduy, Severo. (1969). Escrito sobre un cuerpo: ensayos de crítica (Escritura/ Travestismo). Buenos Aires: Sudamericana.

Sifuentes-Jáuregui, Ben. (1997). Gender Without Limits. Transvestism and Subjectivity in El lugar sin límites. En Daniel Balderston \& Donna J. Guy (eds.), Sex and Sexuality in Latin America. Nueva York: New York University Press.

Sifuentes-Jáuregui, Ben. (2002). Transvestism, Masculinity, and Latin American Literature. Nueva York: Palgrave.

Soto Rodríguez, Mario Andrés. (2014). La patologización de la transexualidad: contemplando posibilidades de resistir desde algunas construcciones identitarias de género no hegemónicas. Cuadernos Inter.c.a.mbio sobre Centroamérica y el Caribe, 11(8), 145-165. Recuperado de http://revistas. ucr.ac.cr/index.php/intercambio/article/view/16721/16219 